\title{
Managing Professional Development Activities for Non-teaching Staff: For Professional Growth
}

\author{
Djonde Frega A. Antiado ${ }^{1}$, Fermin G. Castillo. Jr.,", James Ryan P. Reblando ${ }^{3}$, \\ Maher Ibrahim Tawadrous ${ }^{4}$ \\ ${ }^{1}$ General Education Department, American College of Dubai, Dubai, United Arab Emirates \\ ${ }^{2}$ College of Business Administration, University of Sharjah, Sharjah, United Arab Emirates \\ ${ }^{3}$ College of Business Administration, MENA College of Management, Dubai, United Arab Emirates \\ ${ }^{4}$ General Education Department, City University College of Ajman, Ajman, United Arab Emirates
}

Received November 4, 2020; Revised May 5, 2020; Accepted May 13, 2020

Copyright (C) 2020 by authors, all rights reserved. Authors agree that this article remains permanently open access under the terms of the Creative Commons Attribution License 4.0 International License

\begin{abstract}
A knowledge-based economy, exponential changes in technology, increasing number of diverse students, call for innovativeness, community engagement, stiffer competition and demands for accountability put enormous demands in institutions of higher education. The non-teaching staff had taken significant roles in today's academic work environment. However, the challenges of the 21 st century bring the non-teaching staff to be in front of the process. By using training needs analysis, we can determine what professional development activities to be given. To ensure its sustainability, professional development programs must focus on and benefit the institution which includes both teaching and non-teaching staff. Nonteaching staffs play vital role in the academic environment because they are in the technical and support side of the educational institution. It is very important that nonteaching staffs should also be knowledgeable with their role and participation in the process. This paper is an eye opener to the top management on the value of non-teaching staff as they portray equally important role same as teaching staff.
\end{abstract}

Keywords Professional Development, Non-teaching Staff, Academic Institution, Training Needs Analysis, Competitiveness

\section{Introduction}

Demands in institutions of higher education are becomingly enormous brought about by a knowledge-based economy, exponential changes in technology, increasing number of diverse students, call for innovativeness, community engagement, stiffer competition and demands for accountability. This brings about challenges to the entire academic environment - the teaching and the non-teaching staff to attain the accomplishment of institutional goals in higher education. The non-teaching staff may have taken peripheral roles in the past, however with the enormous challenges faced by institutions of higher learning they need to continually be oriented and learn new roles and participate actively in the process to support the faculty, the institution and its stakeholders. Identifying training needs as part of the professional development program of an institution of higher learning is a vital element of its sustainability. To ensure its sustainability, professional development programs must focus and benefit the institution, and include both teaching and non-teaching staff. Non-teaching staffs play vital roles in the academic environment because they are in the technical and support side of the educational institution.

\section{Literature Review and Studies}

The primary focus of a training needs assessment is to determine performance requirements and the knowledge, skills, abilities and attitudes needed by the institution. A successful training need assessment will facilitate resources to fill in the "gap." The assessment must deal with the need to fulfill the institutions mission and vision, improve efficiency, and raise quality output and services. A needs assessment is the method of identifying the "gap" between the performances required and achieved performance. As the gaps are recognized, they are evaluated to verify the method in which the gaps can be bridged. The outcome of the training needs analysis will aid in the preparation of modules and facilitate the 
development of a training program to close or eliminate the "gaps". In this action research, "gaps" as perceived by the respondents are the identified training interests in the areas professional, personal, and health. The result shall serve as guide for the Guidance and Counseling Center and Human Resource Department in crafting a functional training program that will address the needs of administrative staff of three groups specifically 1-11 months, 1-2 years, and 3 years.

In fact, there are many research and studies that will prove that professional development is a must for any employees in the corporate as well as in academic environment. One of the definition of professional development according to Speck \& Knipe [1] Professional development is learning to earn or maintain professional credentials such as academic degrees to formal coursework, attending conferences, and informal learning opportunities situated in practice. It has been described as intensive and collaborative, ideally incorporating an evaluative stage. Its truth is school setting that it's a matter of learning because non-teaching staff are exposed to different scenario and situations wherein they have to overcome. In fact, non-teaching staff are the frontline of the management to valued students. They have to provide fast and efficient service to them otherwise it will give negative impressions. It is a way to identify the learning needs of the employee for the future development program to promote a high level of job performance. Also a recurrent process that contributes how the employee developed after the course planned and being evaluated. [2]

In fact, many organizations build and establish their foundation through the help on non-academic staff. The performance of non-academic can be seen on how they cope with their day to day work in an academic work environment.

All organization can select the most accurate method, taking into account such factors as organization size, technology, organizational structure, training staff, facilities, and budget. [3] In this research study with less than 10 samples of colleges and universities therefore the challenge is more easier except extracting information may be difficult. Commonly, decision making is very crucial in human life. Most especially if someone belongs to professional environment, so it is very important to obtain outputs with functional use of decision-making skills. [4] In fact, non-academic staff are even expose to decision making as compared to academic/teaching staff to some extent. If the experience of the non-academic staff is weak it is very visible to valued customer's reaction at hand. The research study is anchored in the principle of human resource management "KSA" (knowledge, skills and abilities) a term which was first introduced in US Federal Government. [5]

Where the variables of knowledge, skills and abilities are breakdown into pieces namely.

Knowledge focuses on the understanding of concepts. It is very important that non-academic staff have the knowledge and basic idea about the nature of the business they are dealing with. Since academic environment can be considered as service therefore they have to show knowledge in handling basic information to prospective students in-front. Another thing is the level of maturity of non-academic staff in handling different student inquiry as well solving those issue at hand. If the prospective students are convinced then the possibility that they may enroll to that institution is high. This is very crucial because admission is the first and foremost department where prospective employee inquire for the courses/degrees they are interested with. Knowledge can be acquired by the non-teaching staff in various capacity and means by reading the college and/or university mission and vision. Profile and course offering will also help them to identify the priority and important details to share to valued customers.

Skills. These are the proficiencies developed through training or experience. In the case of non-teaching staff, they came from different and diverse background and inclination, therefore, they bring different skills into it like communication skills, organizing skills and more. As a result, the skills that non-teaching staff may require to be aligned are based on the education system. Prior experience in negotiation may help but it needs to be tested in front of prospective students.

Abilities are the qualities of being able to do something. In the case of non-teaching staff, it is safe to say they have different abilities to share which can be valuable to the institution. The ability to convince people to enroll and trust their future. [6]

Human resources are the backbone of any university, college, or specialized institution. Qualified and dedicated staff are key to ensuring that higher education institutions fulfill their mission of teaching/learning, research, and service to society. [7] Just like faculty member the nonteaching staff also plays vital role in the process. It's like saying that before they come and attend the classroom, the non-teaching staff already take care of them. While if they are inside the classroom then it's the teacher's role that will prevail.

Professional development can play a central role in equipping educational staff with knowledge of the benefits, risks, and consequences of technology. [8] In most occasion it is the non-teaching staff that are the ones who handle the enrolment and faculty members are in advisory role. This means that non-teaching staffs are equally valuable as teaching/faculty members in the institution. The lifelong learning principles is applicable to everyone because it helps us to grow as a person.

With the advent of Knowledge Management in our modern economy today, this rapid growth of information transformation is a great symbol of modern civilization. [9] This simply explains that we have to embrace such changes and challenges that is happening around us. This will help the academic and non-academic staff to be more 
competitive and abreast to the current trends and updates in the practice of education and a lot more. In fact, many professional developmental activities involved the use of mobile platform in the workplace.

In a typical organization, the role of human resources department became strategic in nature because they are the ones who set the qualification framework of non-academic and academic staff in coordination of respective heads/deans as the case maybe. Therefore, HR can be viewed as a strategic department that employs quality in both selection and recruitment of prospective candidates.

The use of ICT (information, communications, and technology) plays vital role in the workplace as it helps the daily work to be effective and efficient in timely manner. [10]. It is important that $\mathrm{HR}$ and academic heads/deans must work hand in hand in the use of ICT in the academic setup because it will facilitate the knowledge transfer across department/units in the organization. In fact, HR play important role in the process because they are highly involved in both academic and non-academic thru training and development.

\section{Methodology}

Descriptive type of research was employed in this research study plus unstructured informal interviewed was done accordingly. A pretest was conducted from five (5) respondents in order to establish the reliability of the questionnaire plus needs to be converted and administered in both English and Arabic language. The final draft of the questionnaire was distributed during the seminar workshop with kind permission from the HR and Top management.

It is important that there is validation of answers directly from the respondents in order to clarify and sort things out accordingly. It aims to gather data, organize, tabulate, depict and describe the data collected. [11] Purposive sampling was used in order to achieved the goal of study which is to unlock and discover the potentials of non-teaching staff while prioritizing their well-being in general

Aside from questionnaire, observation of academic staffs is done in order to see if they really know their work role. Since non-teaching staff are the front liner in the workplace, therefore, they must perform accordingly in order to pursuit their work load. The questionnaires and interviews are the main instruments used in this research study plus taking into consideration different multicultural diversity of non-teaching staffs. The elements of Training Needs Analysis were employed in this research study in order to identify the gap existing and at the same time understand the interest of the non-teaching staff.

\section{Results and Discussion}

Based on the questionnaires and interviewed conducted, the following are the findings and results of the research study. The total respondents accounted for 33 from the total 50 with retrieval rate of $66 \%$. This is due to the fact that many of the non-teaching staff are busy in their assigned work. Both hard copy and soft of the questionnaires were given hence, hard copy is still their preferred choice of answering the questions (accounting for $90 \%$ ) of the reply. Aside from that the language barriers among non-teaching staff as almost half required translation to Arabic and French language. There are 13 males $(39.39 \%)$ and 20 females $(60.60 \%)$ respectively. In terms of age range 21-30, 7 respondents (accounting for $21.21 \%$ ), 31-40, 12 respondents (accounting for $36.36 \%$ ), 41-50, 9 respondents (accounting for $24.24 \%$ ) and lastly 51 above had 6 respondents (accounting for 18.18\%) respectively. In terms of academic degree/certificates, majority of the respondents have a minimum of bachelor's degree (23) accounting for almost $70 \%$ and masters (7) and Doctorate degree (3). And lastly in terms of nationality/citizenship, the majority of the respondents are Arabs with 10, followed by Asian with 7, African 5, American and European with 4 and Canadian 3. This means that in non-teaching staff we have seen multicultural diversity across department/units. This will help each and every one in terms of understanding cultural similarities and difference as the case maybe.

The questionnaires were categorized in two parts namely demographics and direct question related to 3 aspect of professional development namely professional, personal and health. The classification of respondents is non-academic staff with 1 month to 11 months working experience, 1 to 2 years and 3 years above. Each respondent had been asked to evaluate topics for training based on their level of interest. In order to answer the first question, average weighted means per area of training were computed and subsequently ranked. For the second problem, weighted means per topic in each areas of interest in every group of administrative staff were commuted, interpreted and subsequently ranked. Weighted Means were interpreted based on the table below.

Table 1. Interpretation Table of Weighted Means

\begin{tabular}{|c|c|}
\hline Range & Qualitative Interpretation (QI) \\
\hline $1.334-2$ & Strong Interest (STI) \\
\hline $0.667-1.333$ & Some Interest (SMI) \\
\hline $0-0.666$ & No interest (NI) \\
\hline
\end{tabular}


Table 2. Summary Responses across Areas of Training

\begin{tabular}{|c|c|c|c|c|c|c|c|c|c|}
\hline \multirow{3}{*}{ AREAS OF TRAINING } & \multicolumn{9}{|c|}{ RESPONSES OF RESPONDENTS } \\
\hline & \multicolumn{3}{|c|}{ 1-11 months } & \multicolumn{3}{|c|}{$1-2$ years } & \multicolumn{3}{|c|}{$3 \mathrm{yrs}+$} \\
\hline & \multicolumn{2}{|c|}{ W. Mean } & \multirow{2}{*}{$\begin{array}{c}\text { Rank } \\
2\end{array}$} & \multicolumn{2}{|c|}{ W. Mean } & \multirow{2}{*}{$\begin{array}{c}\text { Rank } \\
2\end{array}$} & \multicolumn{2}{|c|}{ W. Mean } & \multirow{2}{*}{$\begin{array}{c}\text { Rank } \\
2\end{array}$} \\
\hline Professional & 1.5 & STI & & 1.628571 & STI & & 1.653333 & STI & \\
\hline Personal development & 1.636364 & STI & 1 & 1.725 & STI & 1 & 1.9 & STI & 1 \\
\hline Health Wellness & 1.159091 & SMI & 3 & 1.325 & SMI & 3 & 1.35 & STI & 3 \\
\hline
\end{tabular}

Table 2 shows the summary responses across areas of training of the non-academic staff. The result indicates that all administrative staff have equal training interest. Personal Development had ranked first, followed by Professional Development and Health Wellness Development topics. Administrative Staff with three or more years stay in the university have strong interest in all areas of training.

Improving Communication Skills, Organizational Skills, Personal and Professional Ethics, Staff Motivation Strategies, Tapping into Your Creativity, Team Building have the same qualitative interpretation of Strong Interest and are ranked as 3.5. Conflict Management $\backslash$ Avoidance \ Resolution was ranked the least with a qualitative interpretation of some interest.

The three category of areas of training are classified as professional, personal and health wellness respectively. The staffs are group into three (3) according to their years of experience working in an academic environment. Most of the non-teaching staffs shift their career in the academe as previously work in a corporate/industry setting. Based on the interview they unanimously answered that they enjoyed working in an academic environment. This is because they love diversity and challenge. Cultural diversity is important for any organization to grow, develop, compete and retain its greatest resource that is human talent. [12] In fact both similarities and differences provides any organization the much needed push or upgrade in terms of manpower development. This is the trend anywhere in the world today and will remain in the coming years. Perhaps the challenge is how we can deal with employees across generations from multi-cultural diverse background and inclination.

Meanwhile both professional and personal development topped the areas of training as most of the non-teaching staff has a potential to be an academic staff in the near future. Some of them are enrolled or holder of MS, MBA, MA and other master's degree level of studies.

Around $75 \%$ of the respondents during the interviewed believed that personal development is very important for their growth as they can bring that experience anywhere they go. Personal development takes place over the course of a person's entire life. [13] The amount of time they spent in training and development will further prepare them for a better work and position in the years ahead.
Table 3. Ranking of Professional Development Topics of employees

\begin{tabular}{|c|c|c|c|}
\hline \multicolumn{4}{|c|}{ PROFESSIONAL DEVELOPMENT TOPICS } \\
\hline TOPICS & WMEAN & QI & RANK \\
\hline $\begin{array}{c}\text { Improving Communication } \\
\text { Skills }\end{array}$ & 2 & STI & 1 \\
\hline Organizational Skills & 2 & STI & 1 \\
\hline $\begin{array}{c}\text { Personal and Professional } \\
\text { Ethics }\end{array}$ & 2 & STI & 1 \\
\hline Staff Motivation Strategies & 2 & STI & 1 \\
\hline Tapping into Your Creativity & 2 & STI & 1 \\
\hline Team Building & 2 & STI & 1 \\
\hline Customer Service & 1.8 & STI & 7 \\
\hline Developing Support Networks & 1.8 & STI & 7 \\
\hline $\begin{array}{c}\text { Time Management } \\
\text { Managing Change }\end{array}$ & 1.8 & STI & 7 \\
\hline $\begin{array}{c}\text { Methods for Keeping Current } \\
\text { in Your Field }\end{array}$ & 1.6 & STI & 10 \\
\hline $\begin{array}{c}\text { Multiculturalism } \backslash \text { Diversity } \\
\text { Intercultural Communication }\end{array}$ & 1.6 & STI & 10 \\
\hline Mentoring New Employees & 1.4 & STI & 10 \\
\hline $\begin{array}{c}\text { Conflict Management } \backslash \\
\text { Avoidance } \backslash \text { Resolution }\end{array}$ & 1.2 & SMI & 14 \\
\hline
\end{tabular}

Developing and Achieving Personal Goals topped the other topics with rank 1 while preventing Job Burnout is at the bottom with a rank of 4 . Administrative Staff in this group are strongly interested in all topics except in Preventing Job Burnout. Based from the ranking, there are 5 topics with same rank such improving communication skills to time management with rank 1, followed by Managing time to diversity with 10 . In the bottom there is mentoring as 13 and conflict management as 14. This simply explains that diversity in the workplace settings may have a common understanding of the practice in an academic setup. While mentoring can be alarming because of cultural differences and experiences which may work or not that's why they are not really into solicited advice.

The conflict management is rank the last among topics because each staffs are not really comfortable in this topic. They remained positive that activities related to team building and improving communication skills are better than any other topics of interest. They value the relationship rather than the work related issue which is very important in the Middle Eastern culture. 
Table 4. Ranking of Personal Development Topics

\begin{tabular}{|c|c|c|c|}
\hline \multicolumn{4}{|c|}{ PERSONAL DEVELOPMENT TOPICS } \\
\hline TOPICS & WMEAN & QI & RANK \\
\hline $\begin{array}{c}\text { Developing and } \\
\text { Achieving Personal } \\
\text { Goals }\end{array}$ & 1.818182 & STI & 1 \\
\hline $\begin{array}{c}\text { Career Planning and } \\
\text { Goal Setting }\end{array}$ & 1.727273 & STI & 2 \\
\hline $\begin{array}{c}\text { Understanding } \\
\text { Nonverbal } \\
\text { Communication }\end{array}$ & 1.681818 & STI & 3 \\
\hline Preventing Job Burnout & 1.318182 & SMI & 4 \\
\hline
\end{tabular}

The respondents believed that their work as non-teaching staff can be temporary as majority of them wants to be in the teaching field if given the chance and opportunity. This is because the remuneration and pay is totally different between the two plus more flexibility.

The choice of career in the academic settings remains to be their ideal choice because of its nature of work that is service oriented rather than technical nor clerical/paper works. As working in a multi-cultural diversity remains to be a combination of joy and fun. The downside exposes that dealing with different language poise a threat somehow in the process of communication therefore, it is important that non-teaching staff should be given language training during their probationary period in order for them to adopt to the work environment.

Results show that Healthy Eating $\backslash$ Weight Loss topped the other topics with rank 1 and Diabetes Education and Health Awareness, Nutrition and Fitness were ranked the least with equal rank of 1-4. All the staff in this group are somewhat interested in all topics except in Healthy Eating and Weight Loss where they are strongly interested. In fact, many colleges and universities have in-house gym and sports facilities wherein both teaching and non-teaching staff can get along. Sports can be a good bonding and past time for both teaching and non-teaching staff because they can release their tensions and pressures received in their day to day work in the academic environment.

Table 5. Ranking of Health Wellness

\begin{tabular}{|c|c|c|c|}
\hline \multicolumn{4}{|c|}{ WELLNESS TOPICS } \\
\hline TOPICS & WMEAN & QI & RANK \\
\hline Healthy Eating $\backslash$ Weight Loss & 1.6 & STI & 1 \\
\hline $\begin{array}{c}\text { Health Fair(e.g. Blood Pressure } \\
\text { Screening, Body Fat Screening, } \\
\text { Cancer Screening, Cholesterol } \\
\text { Screening, Hearing and Vision } \\
\text { Screenings, Mental Health } \\
\text { Screening) }\end{array}$ & 1.3 & SMI & 2 \\
\hline Diabetes Education & 1.2 & SMI & 3.5 \\
\hline $\begin{array}{c}\text { Health Awareness, Nutrition and } \\
\text { Fitness }\end{array}$ & 1.2 & SMI & 3.5 \\
\hline
\end{tabular}

Health wellness program remains to be popular across non-teaching staff with a mean range of 1.2 to 1.6. This simply explains that they are interested to actively participate in any health related program as it is very important to have work life balance. Based on our interviewed many non-teaching staff are also interested to participate in a food expo showcasing different foods across culture. This will surely create more connecting across culture plus camaraderie will be more united and integrated.

Some suggested that wellness program can be integrated with mental health due to the fact that the nature of work is fast phasing and requires mental toughness. This is the area that majority of the respondents keen to be developed in the long term. If the organization has wellness program, they can eventually save a lot in terms of insurance and budget because they have healthy and fit workforce ready for the academic challenges.

Perhaps the critical issue in implementing the wellness program is the time availability and cultural constraints where you cannot really mix both married/unmarried non-teaching staff. Maybe team building with their consent things can achieve with harmony and grace. Overall, they understand the importance of work-life balance is still the most important in the list.

\section{Conclusions and Recommendations}

In general, the study concludes that non-academic staff regardless of the number of years of stay in the university/college are focused more on establishing foundation for their career as manifested by their need for professional development characterized by their need to be trained on Developing and Achieving Personal Goals, Career Planning and Goal Setting, Understanding Nonverbal Communication, and Preventing Job Burnout. Further, it is concluded that the non-academic staff desires to have a good reputation as an effective contributor to the Mission/Vision and Objectives of the university/college early on their careers. Professional Development is seen as catalyst for change in any organization more in a higher education where competition is like a marketplace.

Professional development activities should be given to both academic, administrative and non-academic staff as it should be an on-going process. Each and every non-teaching staff must develop personally and professional and institution must prepare training and development plan as part of the performance appraisal. It is also suggested that a senior non-academic staff must be assigned and act as coordinator of the department. For example a staff with more than 3-5 years experience in the same institution can guide other staff members within the department. Their role is very critical because they act as the mentor/coach of the department. Being the coordinator poises a greater responsibility like taking over to the professional developmental activities for the department. 
This additional role requires minimal honorarium otherwise it will be difficult to implement. We have to understand that in every plans normally involving budget, and budget is one of the sensitive issue that many institutions of higher learning are always into their radar. Institution must understand that their non-teaching staff are the frontline of the institution to prospective clients therefore they are also equally important as academic/teaching staff.

\section{Future Work and Studies}

There are many studies that can be explored accordingly related to academic as well as in non-academic staff contribution to the academic community. Perhaps a good area of research is the competency of the non-academic staff as well as their transition to academic work environment. Another very good area of research can be how to sustain the budget and expenses with respect to professional developmental activities. Many colleges and universities around the world realize that non-academic staffs are equally important as academic/teaching staff. Transition of work from non-teaching to teaching staff can be a good research topic for staff who would like to be part of the teaching profession. Probably, satisfaction of both teaching and non-teaching staff related to their current work can be a good researchable topic in the future.

\section{REFERENCES}

[1] Speck, M \& Knipe, C. "Why can't we get it right? Designing high-quality professional development for standards-based schools." (2 $2^{\text {nd }}$ ed.) Thousand Oaks: Corwin Press, 2005.

[2] Gould, D., Kelly, D., White, I., \& Chidgey, J. "Training needs analysis." A literature review and reappraisal International Journal of Nursing Studies Volume 41, Issue 5, July 2004, Pages 471-486, 2004.

[3] Pajaron, T., "How to Identify Training Needs at Your Organization". Available. [Online]. https://goo.gl/tnbwQk, 2015.

[4] Colakkadioglu, Oguzhan; Celik, D. Billur. "The Effect of Decision-Making Skill Training Programs on Self-Esteem and Decision-Making Styles"- Eurasian Journal of Educational Research, n65 p259-276, 2016.

[5] Troutman, K. K. "Helping Hands Careers in Government: Working for Uncle Sam". The Washington Post. Boisfeuillet Jones Jr. ISSN 0190-8286, 2006.

[6] Lauby, S. "The Difference Between Knowledge, Skills and Abilities" Available. [Online]. https://www.hrbartender.co $\mathrm{m} / 2013$ /recruiting/the-difference-between-knowledge-skill s-and-abilities/, 2013.
[7] Haskins, M., \& Shaffer, G. "Assessing professional development program impact". Strategic HR Review, 10 (1), pp. 15-20, 2011.

[8] Munger, M. H., Campbell, B., \& Banister, S. Technology boot camp: Providing professional development for faculty and supporting active learning environments for students. In M. Searson \& M. Ochoa (Eds.), Proceedings of society for information technology \& teacher education international conference 2014 (pp. 789-793). Chesapeake, VA: AACE., 2014.

[9] Castillo, F. G. "Information and communication technology in todays modern education," Available. https://ieeexplore.ieee.org/abstract/document/5700041 Second International Conference on Engineering System Management and Applications, pp. 1-6 ISBN: 978-1-4244-6520-0, Sharjah, UAE, 2010.

[10] MI Tawadrous, DF Antiado, FG Castillo "Mobile platform in the workplace: The next generation practice in human resource" Procedia-Social and Behavioral Sciences, vol. 219, pp.152-158, Available. [Online]. doi: 10.1016/j.sbspr o.2016.04.058, 2016.

[11] Sheard, J.- "Research Methods" $2^{\text {nd }}$ edition. Information, Systems, and Contexts, Available. [Online]. https://doi.org /10.1016/B978-0-08-102220-7.00018-2 pages 429-452, 2018.

[12] Kulkarni, S. "A study on cultural diversity management for Indian organizations". Procedia - Social and Behavioral Sciences, 37 - Available. [Online]. https://reader.elsevier.c om $/$ reader/sd/pii/S1877042812007720?token=435D9150B 288675472BED49B5FB319D1990F946262410630D5BB0 480D040815A4E16CDC662FC59B38ACA2DEA48DA90 08 - doi: 10.1016/j.sbspro.2012.03.293 pp. $267-276,2012$.

[13] Aubrey, Bob, "Managing Your Aspirations: Developing Personal Enterprise in the Global Workplace, - What is Personal Development? Skills you need. McGraw-Hill, ISBN 978-0-07-131178-6, p. 9, 2010. 